\title{
HUBUNGAN FAKTOR PENDIDIKAN, PEKERJAAN, SIKAP DAN DUKUNGAN KELUARGA TERHADAP IMUNISASI DASAR DI RW 03 KELURAHAN KEDUNG COWEK KENJERAN SURABAYA
}

\author{
Astrida Budiarti \\ STIKes Hang Tuah Surabaya \\ E-mail : as3da_ns@yahoo.com
}

\begin{abstract}
Immunization coverage in Indonesia has not met the target, including in Puskesmas Kenjeran Surabaya. The purpose of this study was to analyze the relationship between education, work, mother's attitudes, and family support toward basic immunization in Puskesmas Kenjeran Surabaya. This study uses an analytic observational design with cross sectional design. Population of all mothers with children aged 0-1 years who visited in Posyandu Cempaka RW 03 Kedung Cowek Surabaya. Sampling technique was simple random sampling with 42 respondents. The instruments used questionnaires and health cards. Data analysis uses Chi-Square. The results show there is a correlation of education toward basic immunizations, with a value of $p=0,001$. There is a correlation between mother work toward basic immunizations, with a value of $p=0,001$. There is a correlation between mother's attitude toward basic immunizations, with a value $p=0,030$. There is a correlation of family support toward basic immunizations, with a value $p=0.001$. Based on this study, education is necessary to increase maternal awareness about the importance of complete basic immunization for their children. In addition, increasing the active role of officer to motivating mothers to bring their children for immunizations.
\end{abstract}

Keywords : education, work, mother's attitudes, family support, basic immunization

Abstrak : Cakupan imunisasi di Indonesia belum memenuhi target termasuk di Puskesmas Kenjeran Surabaya Tujuan dari penelitian ini untuk menganalisis hubungan antara pendidikan, pekerjaan, sikap ibu, dukungan keluarga terhadap imunisasi dasar pada anak di Puskesmas Kenjeran Surabaya. Studi ini menggunakan desain observasional analitik dengan cross sectional. Populasi semua ibu dengan anak berusia 0-1 tahun yang berkunjung di posyandu cempaka RW 03 Kelurahan Kedung Cowek Surabaya. Teknik sampling adalah simple random sampling dengan 42 responden. Instrumen menggunakan kuesioner dan kartu sehat. Analisis data menggunakan Chi-Square. Hasil menunjukkan terdapat korelasi pendidikan terhadap kepatuhan ibu melaksanakan imunisasi dasar, $p=0,001$. Terdapat korelasi pekerjaan terhadap kepatuhan ibu melaksanakan imunisasi dasar, $p=0,001$. Terdapat korelasi sikap ibu terhadap kepatuhan ibu melaksanakan imunisasi dasar, $p=0,030$. Terdapat korelasi dukungan keluarga terhadap kepatuhan ibu melaksanakan imunisasi dasar, dengan nilai $p=0,00$. Berdasarkan hasil penelitian ini diharapkan adanya pemberian edukasi berupa penyuluhan dan sosialisasi untuk meningkatkan kesadaran ibu tentang pentingnya pemberian imunisasi dasar lengkap bagi anaknya. Selain itu, meningkatkan peran aktif kader dalam memotivasi para ibu agar mau membawa anaknya untuk imunisasi di Puskesmas.

Kata kunci : imunisasi dasar, pendidikan, pekerjaan, sikap, dukungan keluarga

\section{PENDAHULUAN}

Imunisasi merupakan usaha untuk menjadikan seseorang menjadi kebal terhadap penyakit tertentu dengan menyuntikkan vaksin. Vaksin merupakan kuman hidup yang dilemahkan atau kuman mati atau zat yang bila dimasukkan ke tubuh menimbulkan kekebalan terhadap penyakit tertentu (Tresnawati, 2012:184). Manfaat imunisasi sangat besar dalam mencegah penyakit menular. Namun, pada kenyataannya cakupan imunisasi di Indonesia belum memenuhi target termasuk Puskesmas Kenjeran Surabaya. Kondisi yang mempengaruhi adalah tingkat pendidikan dan sikap ibu yang rendah sehingga ibu kurang mengetahui manfaat dari imunisasi dan selain itu, ibu tidak menginginkan anaknya rewel dan panas setelah melakukan imunisasi karena bias menganggu pekerjaan ibu. Selain itu juga karena dukungan dari keluarga yang kurang. Hal lain yang mempengaruhi karena ibu tidak mau meninggalkan pekerjaannya.

Rata-rata imunisasi di Indonesia hanya $72 \%$ artinya angka di beberapa daerah dan kota sangat rendah. Kota Surabaya sendiri menurut Dinas Kesehatan Kota Surabaya, data cakupan imunisasi dasar tahun 2015 tidak mencapai target, sebab presentase cakupan imunisasinya hanya mencapai $86,8 \%$ padahal, target untuk cakupan imunisasi sebanyak 93\%. 
Hasil wawancara dengan petugas Puskesmas Kenjeran cakupan imunisasi masih tergolong rendah dan di tahun 2016 ada sedikit peningkatan tetapi belum signifikan. Serta, Puskesmas Kenjeran termasuk dalam Puskesmas dengan cakupan imunisasi rendah dari 62 Puskesmas di Wilayah Dinas Kesehatan Kota Surabaya (Data Puskesmas Kenjeran, 2016).

Pelaksanaan imunisasi yang tidak
efektif disebabkan adanya faktor ketidaktahuan, ketidakmampuan dan ketidakmauan keluarga mengenali persepsi mereka terhadap kesehatan, penyebab dan pencegahan penyakit yang berbeda oleh karena adanya perbedaan latar belakang, pengalaman, sosial budaya, ekonomi, pendidikan antara petugas kesehatan dan masyarakat (Sarwono, 2006). Imunisasi pada balita yang merupakan program imunisasi wajib pemerintah, bila tercapai dapat menurunkan angka infeksi penyakit TBC, campak, difteri, hepatitis, dan poliomyelitis. Mengingat dampak tidak diberikan imunisasi adalah dapat menurunkan kekebalan tubuh pada anak (DepKes RI, 2010).

Upaya untuk meningkatkan kepatuhan ibu adalah dengan pendekatan pada ibu bayi dan keluarga, penyebaran brosur, pertemuan rutin kesehatan, ataupun dengan dilakukan penyuluhan oleh petugas kesehatan yang meliputi: pengertian, manfaat, macam, kapan diberikan dan frekuensi pemberian imunisasi. Serta, adanya kunjungan ke rumah warga dari petugas kesehatan puskesmas untuk memberi edukasi dan melakukan kerjasama dengan organisasi untuk meningkatkan kesadaran masyarakat mendatangi Puskesmas untuk imunisasi.

\section{METODE PENELITIAN}

Penelitian menganalisis adanya hubungan antara pendidikan, pekerjaan, sikap ibu, dukungan keluarga terhadap imunisasi dasar pada anak di Puskesmas Kenjeran Surabaya. Populasi penelitian ini adalah semua ibu yang memiliki anak usia 01 tahun yang berkunjung di Posyandu Cempaka RW 03 Kelurahan Kedung Cowek Surabaya. Sampel penelitian ini ibu yang memiliki anak usia 0-1 tahun yang berkunjung di Posyandu Cempaka RW 03 Kelurahan Kedung Cowek Surabaya berjumlah 42 orangy ang memenuhi kriteria inklusi dan eksklusi. Teknik sampling dalam penelitian ini yaitu probability sampling dengan menggunakan simple random sampling. Penelitian dilakukan selama 2 Bulan. Uji statistik yang digunakan adalah uji Chi-Square.

\section{HASIL PENELITIAN}

Tabel 1 Karakteristik Responden Berdasarkan Tingkat Pendidikan Di RW 03 Kelurahan Kedung Cowek Kenjeran Surabaya

\begin{tabular}{ccc}
\hline Tingkat Pendidikan & $\begin{array}{c}\text { Frekuensi } \\
(\mathbf{f})\end{array}$ & Prosentase (\%) \\
\hline Tidak Sekolah & 1 & 2,4 \\
SD & 8 & 19 \\
SMP & 12 & 28,6 \\
SMA & 16 & 38,1 \\
PT & 5 & 11,9 \\
\hline Total & $\mathbf{4 2}$ & $\mathbf{1 0 0}$ \\
\hline
\end{tabular}

Tabel 2 Karakteristik Responden Berdasarkan Status Pekerjaan Di RW 03 Kelurahan Kedung Cowek Kenjeran Surabaya

\begin{tabular}{ccc}
\hline Pekerjaan & $\begin{array}{c}\text { Frekuensi } \\
(\mathbf{f})\end{array}$ & Persentase (\%) \\
\hline Tidak Bekerja & 30 & 71,4 \\
Bekerja & 12 & 28,6 \\
\hline Total & 42 & 100 \\
\hline
\end{tabular}


Tabel 3 Karakteristik Responden Berdasarkan Sikap Ibu Di RW 03 Kelurahan Kedung Cowek Kenjeran Surabaya

\begin{tabular}{ccc}
\hline Sikap lbu & $\begin{array}{c}\text { Frekuensi } \\
(\mathbf{f})\end{array}$ & Persentase (\%) \\
\hline Setuju & 15 & 35,7 \\
Ragu - ragu & 22 & 52,4 \\
Tidak Setuju & 5 & 11,9 \\
\hline Total & 42 & 100 \\
\hline
\end{tabular}

Tabel 4 Karakteristik Responden Berdasarkan Dukungan Keluarga Di RW 03 Kelurahan Kedung Cowek Kenjeran Surabaya

\begin{tabular}{ccc}
\hline Dukungan Keluarga & $\begin{array}{c}\text { Frekuensi } \\
(\mathbf{f})\end{array}$ & Persentase (\%) \\
\hline Mendukung & 10 & $23,8 \%$ \\
Tidak Mendukung & 32 & $76,2 \%$ \\
\hline Total & 42 & 100 \\
\hline
\end{tabular}

Tabel 5 Karakteristik Responden Berdasarkan kelengkapan Imunisasi Di RW 03 Kelurahan Kedung Cowek Kenjeran Surabaya

\begin{tabular}{ccc}
$\begin{array}{c}\text { Kelengkapan } \\
\text { Imunisasi }\end{array}$ & Frekuensi (f) & Persentase (\%) \\
\hline Lengkap & 10 & 23,8 \\
Tidak Lengkap & 32 & 76,2 \\
\hline Total & 42 & 100
\end{tabular}

Tabel 6 Hubungan Pendidikan Ibu Terhadap Kelengkapan Imunisasi Di RW 03 Kelurahan Kedung Cowek Kenjeran Surabaya

\begin{tabular}{ccccccc}
\hline \multirow{2}{*}{$\begin{array}{c}\text { Pendi } \\
\text { dikan } \\
\text { lbu }\end{array}$} & \multicolumn{4}{c}{ Kelengkapan imunisasi } & \multicolumn{2}{c}{ Total } \\
\cline { 2 - 6 } & \multicolumn{3}{c}{ Lengkap } & \multicolumn{2}{c}{ Tidak Lengkap } & \multicolumn{2}{c}{} \\
\hline Dasar & 1 & 10 & 9 & 90 & 10 & 100 \\
Mene-ngah & 3 & 13,6 & 19 & 86,4 & 22 & 100 \\
Tinggi & 6 & 60 & 4 & 40 & 10 & 100 \\
\hline Total & 10 & \multicolumn{5}{c}{ Nilai uji statistik Chi-Square $\mathbf{0 , 0 0}$} \\
\hline
\end{tabular}

Tabel 7 Hubungan Pekerjaan Ibu Terhadap Kelengkapan Imunisasi Di RW 03 Kelurahan Kedung Cowek Kenjeran Surabaya

\begin{tabular}{ccccccc}
\hline \multirow{2}{*}{$\begin{array}{c}\text { Pekerjaan } \\
\text { Ibu }\end{array}$} & \multicolumn{3}{c}{ Kelengkapan imunisasi } & \multicolumn{2}{c}{ Total } \\
\cline { 2 - 6 } & \multicolumn{3}{c}{ Lengkap } & \multicolumn{2}{c}{ Tidak Lengkap } & \multicolumn{2}{c}{ (\%) } & $(\mathrm{f})$ & $(\%)$ & \\
\cline { 2 - 6 } Tidak Bekerja & 2 & 6,7 & 28 & 93,3 & 30 & 100 \\
Bekerja & 8 & 66,7 & 4 & 33,3 & 12 & 100 \\
\hline Total & 10 & \multicolumn{3}{c}{ Nilai uji statistik Chi-Square $\mathbf{0 , 0 0}$} \\
\hline
\end{tabular}


Tabel 8 Hubungan Sikap Ibu Terhadap Kelengkapan Imunisasi Di RW 03 Kelurahan Kedung Cowek Kenjeran Surabaya

\begin{tabular}{|c|c|c|c|c|c|c|}
\hline \multirow{3}{*}{ Sikap Ibu } & \multicolumn{4}{|c|}{ Kelengkapan imunisasi } & \multirow{2}{*}{\multicolumn{2}{|c|}{ Total }} \\
\hline & \multicolumn{2}{|c|}{ Lengkap } & \multicolumn{2}{|c|}{ Tidak Lengkap } & & \\
\hline & (f) & $(\%)$ & (f) & (\%) & $\mathrm{N}$ & $\%$ \\
\hline Setuju & 7 & 46,7 & 8 & 53,3 & 15 & 100 \\
\hline Ragu- Ragu & 2 & 9,1 & 20 & 90,9 & 22 & 100 \\
\hline Tidak Setuju & 1 & 20 & 4 & 80 & 5 & 100 \\
\hline Total & 10 & & 32 & & 42 & 100 \\
\hline
\end{tabular}

Tabel 9 Hubungan Dukungan Keluarga Terhadap Kelengkapan Imunisasi Di RW 03 Kelurahan Kedung Cowek Kenjeran Surabaya

\begin{tabular}{ccccccc}
\hline \multirow{2}{*}{$\begin{array}{c}\text { Dukungan } \\
\text { Keluarga }\end{array}$} & \multicolumn{2}{c}{ Kelengkapan Imunisasi } & \multicolumn{2}{c}{ Total } \\
\cline { 2 - 7 } & $(\mathrm{f})$ & $(\%)$ & $(\mathrm{f})$ & $(\%)$ & $\mathrm{N}$ & $\%$ \\
\hline Mendukung & 9 & 90 & 1 & 10 & 10 & 100 \\
Tidak Mendukung & 1 & 3,1 & 31 & 96,9 & 32 & 100 \\
\hline Total & 10 & \multicolumn{3}{c}{ Tidak Lengkap } & 42 & 100 \\
\hline & Nilai uji statistik Chi-Square $\mathbf{0 , 0 0}$
\end{tabular}

\section{PEMBAHASAN}

\section{Hubungan Pendidikan Terhadap Imunisasi Dasar Di RW 03 Kelurahan Kedung Cowek Kenjeran Surabaya}

Hasil penelitian menunjukkan bahwa terdapat hubungan antara pendidikan dengan imunisasi dasar di RW 03 Kelurahan Kedung Cowek Kenjeran Surabaya. Ibu dengan pendidikan tinggi melaksanakan imunisasi lengkap sebesar $60 \%$. Sedangkan ibu dengan pendidikan dasar didapatkan $90 \%$ tidak lengkap dalam pemberian imunisasi. Menurut pemahaman kognitif, belajar adalah suatu proses usaha yang melibatkan aktivitas mental yang terjadi dalam diri manusia sebagai akibat dari proses interaksi aktif dengan lingkungannya untuk memperoleh suatu perubahan dalam bentuk pengetahuan, pemahaman, tingkah laku, keterampilan, dan nilai sikap yang bersifat relatif dan membekas. Seseorang dengan pendidikan tinggi memiliki wawasan yang lebih terkait kesehatan serta mampu menganalisa manfaat imunisasi lebih besar dari pada dampaknya.
Hal ini didukung oleh penelitian yang dilakukan oleh Novitasari (2012) yang menyatakan terdapat hubungan bermakna antara pendidikan dan pengetahuan terhadap pemberian imunisasi dasar. Seseorang dengan pengetahuan yang lebih akan memilih untuk melakukan imunisasi dasar, karena manfaat imunisasi dasar yang bagus dalam menangkal penyakit yang bisa dicegah dengan imunisasi. Tetapi untuk masyarakat yang memiliki pendidikan rendah maka kemampuan untuk menganalisa informasi juga akan terbatas.

\section{Hubungan Pekerjaan Terhadap Imunisasi Dasar Di RW 03 Kelurahan Kedung Cowek Kenjeran Surabaya Hasil penelitian menunjukkan} bahwa terdapat hubungan antara pekerjaan ibu dengan kelengkapan imunisasi dasar. Menurut penelitian yang dilakukan oleh Dian irawati (2011) menyatakan terdapat hubungan bermakna antara status pekerjaan ibu dengan ketepatan pelaksanaan imunisasi DPT Combo dan Campak. Ibu yang bekerja lebih terfasilitasi dalam mendapat informasi terkait imunisasi, 
meskipun pekerjaan menyita waktu dan mempengaruhi kehidupan keluarga, sedangkan ibu yang tidak bekerja tidak lengkap dalam memberikan imunisasi dasar (93,3\%). Perempuan yang tidak bekerja memiliki waktu lebih untuk saling bertukar pendapat dan berinteraksi dengan orang lain, tetapi tanpa dasar pengetahuan yang memadai. Pada komunitas ibu yang tidak bekerja, sikap dan perilaku merekam lebih baik dalam memberikan imunisasi dasar dibanding ibu yang bekerja, karena mereka memiliki banyak waktu untuk mengantarkan anaknya mendapatkan imunisasi.

\section{Hubungan Sikap Terhadap Imunisasi Dasar Di RW 03 Kelurahan Kedung Cowek Kenjeran Surabaya}

Ada hubungan sikap ibu terhadap kepatuhan ibu melaksanakan imunisasi. Ibu dengan sikap tidak setuju didapatkan $90 \%$ tidak lengkap dalam pemberian imunisasi pada anaknya. Friedman (1998) dikutip dari Setiadi (2008) membagi 5 tugas keluarga dalam bidang kesehatan yang harus dilakukan, salah satunya adalah mempertahankan hubungan timbal balik antara keluarga dan lembaga kesehatan (pemanfaatan fasilitas kesehatan yang ada). Hubungan yang sifatnya positif akan memberi pengaruh yang baik pada keluarga mengenai fasilitas kesehatan. Diharapkan dengan hubungan yang positif terhadap pelayanan kesehatan akan merubah setiap perilaku anggota keluarga mengenai sehat sakit. Berdasarkan hasil penelitian di lapangan menunjukkan bahwa ibu yang memiliki sikap setuju dengan kelengkapan imunisasi dasar lengkap, dikarenakan agar anak bebas dari penyakit dan memberikan kekebalan pada bayi atau mencegah penyakit sehingga angka morbiditas, mortalitas, dan kecacatan dapat ditekan seminimal mungkin.

\section{Hubungan Dukungan Keluarga Terhadap Imunisasi Dasar Di RW 03}

\section{DAFTAR PUSTAKA}

Data Puskesmas Kenjeran (2016). Data Kesehatan PKM Kenjeran

Depkes RI. (2010). Buku kesehatan ibu dan anak Provinsi Jawa Timur. Indonesia. kemungkinan lebih sulit memperoleh informasi. Hasil penelitian juga menunjukkan bahwa ibu yang tidak bekerja mayoritas ibu

Kelurahan Kedung Cowek Kenjeran Surabaya

Ada hubungan dukungan keluarga terhadap kepatuhan ibu melaksanakan imunisasi. Notoadmojo (2010) mengidentifikasikan beberapa jenis dukungan yang meliputi ekspresi perasaan positif menunjukkan bahwa seseorang diperlukan dengan rasa penghargaan yang tinggi, ekspresi persetujuan dengan atau pemberitahuan tentang ketepatan keyakinan dan perasaan seseorang. Ajakan untuk membuka diri dan mendiskusikan keyakinan dan sumber juga merupakan bentuk dukungan sosial. Untuk mewujudkan sikap menjadi suatu perbuatan yang nyata diperlukan faktor pendukung atau suatu kondisi yang memungkinkan, antara lain adalah fasilitas. Sikap ibu yang positif terhadap imunisasi harus mendapat konfirmasi dari suaminya dan ada fasilitas imunisasi yang mudah dicapai, agar ibu tersebut mengimunisasi anaknya. Disamping factor fasilitas, juga diperlukan dukungan dari pihak lain, misalnya suami/istri/orang tua/mertua.

Berdasarkan hasil penelitian di lapangan menunjukan bahwa sebagian kecil keluarga mendukung imunisasi dasar lengkap, dan sebagian besar keluarga tidak mendukung imunisasi dasar lengkap. Dikarenakan faktor ketidakmampuan dan ketidakmauan keluarga dalam mengenali masalahnya termasuk persepsi mereka terhadap kesehatan.

\section{KESIMPULAN DAN SARAN}

1. Ada hubungan antara pendidikan dan pekerjaan dengan kepatuhan ibu melaksanakan imunisasi dasar di Puskesmas Kenjeran Surabaya.

2. Ada hubungan antara sikap ibu dan dukungan keluarga dengan kepatuhan ibu melaksanakan imunisasi dasar di Puskesmas Kenjeran Surabaya.

Dian Irawati. (2011). Gambaran Imunisasi Pada Balita. Skripsi tidak dipublikasikan. 
Notoatmodjo, Soekidjo. (2010). Promosi kesehatan dan perilaku kesehatan. Jakarta: Rineka Cipta

Novitasari. (2012). Panduan Panduan praktik laboratorium klinik Bayi baru lahir dan kontrasepsi. Jakarta: Salemba Medik

Sarwono.(2006).IImu Kandungan. Jakarta:

Bina Pustaka
Tresnawati, Frisca. (2012). Asuhan kebidanan panduan lengkap menjadi bidan profesional jilid 1. Jakarta: Prestasi Pustaka Publisher

Setiadi, 2008. Konsep Dan Penulisan Riset Keperawatan. Yogyakarta : Graha ilmu 